Justice, R. S. Kalucy, H. A. Kazi, N. Kazmy, K. M. G. Keddie, B. K. Khetarpal, J. M. Lawrence, E. Ledermann, F. Lieh-Mak, C. M. W. Logan, A. C. Macfie, M. E. Mackay, T. H. R. Macleod, K. J. MacRitchie, M. E. Martin, R. J. McClelland, J. McCurley, W. G. McGhee, E. K. McLean, A. McQuaid, S. M. Metcalf, I. H. Mian, M. A. Mian, W. I. Mikhail, Dennis H. Miller, H. G. Morton, M. D. Mulcahy, R. M. Murray, D. H. Myers, M. Nicholas,
O. A. Odejide, M. O. Olatawura, J. E. Oliver, K. B. C. O'Sullivan, E. M. Rich, M. A. Rowton-Lee, J. Rutter, M. Sandler, E. R. Sethna, I. R. Sherret, K. Sinanan, A. Sittampalam, J. A. Snowdon, U. Sreenivasan, R. S. Stern, M. J. Stevens, H. J. Stott, D. A. Sturgeon, J. R. Theobalds, R. P. M. Urquhart, D. J. West, A. H. Wilkinson, A. M. Wilson, J. P. R. Young.

\title{
New Affiliates and New Associates
}

Under the revised Bye-Laws it is now possible for the College to register New Affiliates and New Associates. No more than ten of each may be registered in one year, and no more than one hundred of each may be registered at any time.

New Affiliates must be medically qualified and New Associates must be non-medically qualified. The Court of Electors has suggested that, in general, New Affiliates are not expected to be psychiatrists. However, both groups should be drawn from members of professions whose work is related to psychiatry, in practice or research, and who would be regarded as valuable contributors to the work and standing of the College.

New Affiliates and New Associates pay an annual subscription to the College: at present this is $£ 60$ and $£ 35$ respectively. They receive the Journal and Bulletin and notices of all general, quarterly and scientific meetings, which they can attend. They can join appropriate sections of the College. They do not have a vote in the affairs of the College.

A person may apply or be nominated for registration to the Court of Electors by completion of a brief curriculum vitae on a form obtainable from the College and with the support of at least two Members or Fellows of the College (who should not be members of the Court of Electors at the time of nomination or recommendation).

All submissions for registration should be sent to the Registrar of the College by 30 September each year, for consideration by the Court of Electors in the following year.

\section{Comments on the Report of the British Paediatric Association Working Party on Cystic Fibrosis by the Child and Adolescent Psychiatry Specialist Section}

This was a well-written, concise report of a committee whose terms of reference were 'to assess the advantages and disadvantages of regional centres for cystic fibrosis'.

Figures are given to confirm that children with this disorder are growing up and are out-living paediatric services. The best survival rates, $80 \%$ living to age 20 are found in Melbourne, Australia. In this country, $80 \%$ do survive until age 9, but the various figures given for different centres do not seem strictly comparable.

The committee carried out a survey of all paediatricians in the United Kingdom to find out the present state for patients with cystic fibrosis. Data on 4,557 patients, 2,416 males and 2,141 females were collected. It was found that female mortality was greater than for males, that 965 patients were now aged between 10 and 14 and the majority would survive to become 'adult patients'. Survival was better at a large centre, of which there are 16.
The advantages of large, specialised centres are:

(a) for patients: longevity;

(b) for staff: development of experience and expertise in research;

(c) ease of administration. The disadvantages of the large centres:

(a) for patients: inconvenience and expense of travel, risk of cross infection, local staff will be at a loss in an emergency;

(b) falling off of interest and expertise in local staff.

Recommendations include the establishment of regional cystic fibrosis reference centres, but where there is more than one paediatrician in a local hospital, one should take particular interest. Thus some attempt is to be made to keep 
the advantages of a larger regional centre, with fostering of interest and maintaining some expertise locally. All patients to be notified to the regional centre. Other recommendations are made concerning staff for the regional centres and it is suggested that this can be achieved by redeployment. It is also suggested that an adult physician, probably one with an interest in respiratory disease, should be identified to work with the cystic fibrosis paediatrician and joint adolescent clinics set up. Finally, the regional centres should pool data for research.
Overall, this is a very sensible compromise, but one wonders how it will work in practice. It always needs an enthusiast to deal with long term handicap and they are not always neatly arranged as hoped in these recommendations.

The report is perhaps particularly interesting for the Child and Adolescent Psychiatry Specialist Section as it illustrates a general problem of who will care for the adult long term handicapped and how will this be done.

March 1986

\section{Correspondence}

\section{British psychiatrists in Canada \\ DeAr SIRS}

Further to G. M. Green's article about British psychiatrists in Canada, (Bulletin, April 1985, 9, 77-78) I would like to add to the comments of other correspondents on this subject.

In the Province of Ontario psychiatrists in mental hospitals have been in dispute with the Government for almost a year over working conditions and staffing levels among other things.

Because of this dispute we recommend that anyone applying for an appointment in the Ontario Psychiatric Hospital system should get information on the present status of this dispute. Contact Dr John C. Deadman, Ontario Psychiatric Hospitals \& Hospital Schools Medical Staff Association, c/o Hamilton Psychiatric Hospital, Box 585, Hamilton, Ontario, Canada L8N 3K7.

John C. Deadman

\section{The Mental Health Act}

DeAr Sirs

Dr L. D. Culliford (Bulletin, February 1986, 10, 38) has pointed out one area of dispute where the Mental Health Act is less than clear and entrusts eventual clinical responsibility and interpretation to the attending physician's judgement. Recently we encountered another situation when the Act proved unclear.

A severely depressed middle-aged lady on a Section 2 , who was refusing food and drink, was felt to require a course of ECT. As she was unable to consent, the relevant office of the MHA Commission was contacted and a second opinion (Section 58) was obtained. A course of 12 ECT was recommended. This would normally involve a time span of six weeks giving ECT biweekly.

Though the patient's condition improved somewhat, the Section 2 expired before an adequate course of ECT could be administered. The patient became informal and did not consent to further ECT which were felt necessary.
Under the circumstances, should a Section 3 be invoked and the ECT continued though there may not be enough grounds clinically to justify this decision? Or should ECT, as recommended by the approved doctor from the MHA Commission under Section 58, be continued even though the patient was now informal and clearly did not consent to ECT but was still in need of it?

The MHA $1983^{1}$ recommends that 'A course of treatment or plan of treatment may be continued if the patient has withdrawn consent, if the RMO considers that the discontinuation of the treatment or plan of treatment would cause serious suffering to the patient. In all such cases treatment must cease as soon as its cessation will no longer cause serious suffering'.

The implications of some of the terms are debatable. In this case the patient, though clinically less depressed, was well enough to commit suicide. Does the authority of the treatment (12 ECTs) recommended under Section 58 extend till the course is completed or does this authority get invalidated once the other Section (in this case Section 2) expires?

Middlesex/St Luke's Hospital

P. CHOWDHURY

London

Bethlem Royal Hospital

R. S. SiWACH

Beckenham, Kent

REFERENCE

'Mental Health Act (1983). Memorandum on Parts I to VI, VIII and $X$. London: Department of Health and Social Security.

\section{Alcoholism and the Mental Health Act}

\section{Dear SIRS}

In an earlier issue of the Bulletin (February 1986, 10, 38), Mr G. K. Roberts, an official of the Medical Defence Union, while responding to Dr Culliford's query on the above subject, appears to be suggesting that although alcoholism per se does not justify detention under the provisions of the Mental Health Act 1983, delirium tremens may justify detention under the provisions of 